\title{
EXTRACTION OF BAMBOO SHOOT SHELL FIBERS BY THE ULTRASOUND-ASSISTED ALKALI-OXYGEN BATH METHOD
}

\author{
YINZHI YANG,${ }^{*, * *,}$ MENGTING ZHU, ${ }^{*, * *,}$ FANGWEI FAN,,${ }^{*, * *}$ KAIYANG FANG,,${ }^{*, * *}$ \\ JINPENG XIE, ${ }^{* * * * *}$ ZHONGMIN DENG ${ }^{* * * * * *}$ and XINWANG CAO ${ }^{* * * *}$ \\ "College of Textiles Science and Engineering, Wuhan Textile University, \\ Wuhan 430073, China \\ ${ }^{* * *}$ National Engineering Laboratory for Advanced Yarn and Fabric Formation and Clean Production, \\ Wuhan Textile University, Wuhan 430073, China \\ ${ }^{* * *}$ College of Applied Technology, Wuhan Technology and Business University, Wuhan 430065, China \\ **** State Key Laboratory of New Textile Materials and Advanced Processing Technologies, \\ Wuhan Textile University, Wuhan 430073, China \\ $₫$ Corresponding authors: X. Cao, aswang1984@163.com, Z. Deng, hzcad.deng@foxmail.com \\ ${ }^{\S}$ Authors contributed equally to this work
}

Received March 20, 2021

Herein, bamboo shoot shell fibers were extracted by the ultrasound-assisted alkali-oxygen bath method. The effects of sodium hydroxide and hydrogen peroxide dosage, temperature and treating time on degumming properties were discussed. Taking the degumming rate as the index, the optimum technological parameters of alkali oxygen bath degumming were obtained by orthogonal experiments as follows: scouring temperature was $95^{\circ} \mathrm{C}$, alkali boiling time of 120 minutes, sodium hydroxide dosage of $20 \mathrm{~g} / \mathrm{L}$, hydrogen peroxide dosage of $24 \mathrm{~mL} / \mathrm{L}$, and the corresponding degumming rate was $70.07 \%$. The structure of bamboo shoot shell fibers was examined by infrared spectroscopy, thermogravimetric analysis and scanning electron microscopy. The results showed that pectin, lignin and hemicelluloses were effectively removed from bamboo shoot shell fibers after degumming.

Keywords: bamboo shoot shell fibers, ultrasonic, alkali-oxygen bath, degumming rate

\section{INTRODUCTION}

Natural cellulose fibers are abundantly available all over the world and easy to obtain. Cellulose and its derivatives are renewable, environmentally friendly, natural and biodegradable. ${ }^{1-3}$ Due to its excellent mechanical properties, cellulose is often added into polymer matrix systems to prepare high-performance composites. $^{4,5}$ As a practically inexhaustible biopolymer, cellulose has been considered as a promising and sustainable raw material for the future chemical industry. ${ }^{6,7}$

Bamboo, as one of cellulose resources, is an economic, eco-friendly and sustainable material. In areas of the world facing growing shortages of wood, ${ }^{8,9}$ bamboo products are increasingly used as wood substitutes. ${ }^{10}$ Compared with most wood, bamboo shows similar or better physical and mechanical properties, and it can be processed into composite materials like wood, especially rare hardwood. ${ }^{11,12}$ As one of the fastest growing woody plants in the world, bamboo has always been the most common plant for the production of various household products. $^{13}$

The bamboo shoot shell is the outer skin of the bamboo shoot, which protects it. The bamboo shoot shell is a by-product of the bamboo shoot industry. As the growth cycle of bamboo is short, and the bamboo shoot shell, which is rich in cellulose, results in high yields, it has been considered to be applied in textile materials. ${ }^{14}$ Bamboo shoot shell resources are very rich, but their utilization rate is very low. In recent years, bamboo shoot shell has been often seen abandoned on roadsides, which is not only a waste of valuable plant resources, but also seriously pollutes the environment. At present, 
much research is focused on medicinal uses of bamboo shell and edible bamboo fibers. ${ }^{15,16}$ Moreover, bamboo shoot shell is a rich source of natural fibers, with properties similar to those of bast fibers. ${ }^{17}$ The development of bamboo shoot shell fibers can not only mitigate the gap between the supply of raw materials for natural fibers and the demand, but can be also beneficial to the protection of the environment. The development of bamboo shoot shell fiber opens up a new way for the rational utilization of the bamboo shoot shell resource, and is also conducive to the development of textile fibers.

So far, there have been a large number of reports on the degumming of bast fibers. ${ }^{18,19}$ As well known, the purpose of degumming is to obtain cellulose fibers with excellent performance. At present, the most commonly used degumming method is traditional hightemperature alkali boiling, followed by a bleaching process. This procedure is not only time-consuming, but also pollutes the environment with resulting wastewater. Moreover, the fibers obtained by this process often cannot achieve the expected performance..$^{20,21}$

In the present study, the ultrasound-assisted alkali oxygen bath method was used to extract bamboo shoot shell fibers. This extraction method has the advantages of high degumming rate, environmental protection and simple operation. The morphology, chemical structure, crystallinity and thermal properties of the extracted bamboo shoot shell fiber were fully characterized by scanning electron microscopy, infrared spectroscopy and thermogravimetric analysis. The purpose of the study has been to provide a starting point for the development and application of bamboo shoot shell products.

\section{EXPERIMENTAL Materials}

Mature naturally fallen bamboo shoot shells were collected from the bamboo forest in Wuhan City, Hubei Province. The chemicals used in the study, such as $98 \%$ sulfuric acid, $\mathrm{NaOH}, 30 \% \quad \mathrm{H}_{2} \mathrm{O}_{2}$, sodium metasilicate nonahydrate, sodium tripolyphosphate and others, were laboratory grade (Aladdin Chemical Registration Company, Shanghai, China), and used without further purification.

\section{Pretreatment of bamboo shoot shell}

The bamboo shoot shell was cut to a length of about $2.5 \mathrm{~cm}$, and the impurities and fluff from the surface were removed with warm water $\left(50^{\circ} \mathrm{C}\right)$. The washed bamboo shoot shell was dried at $75^{\circ} \mathrm{C}$ for 24 h. The chopped fiber segments were divided into four groups (5 $\mathrm{g}$ in each group), and were pretreated with ultrasound, at a bath ratio of 1:40, temperature of 45 ${ }^{\circ} \mathrm{C}$, and ultrasonic frequency of $40 \mathrm{KHz}$. After the ultrasonic treatment with water for $20 \mathrm{~min}$, the corresponding dosage of $3 \mathrm{~g} / \mathrm{L}$ sodium hydroxide was added into the bath for $30 \mathrm{~min}$. The samples were washed to neutral $\mathrm{pH}^{22}$

\section{Extraction of bamboo shoot shell fibers}

Through a large number of prior experiments, it was found that the main factors affecting degumming are the amount of sodium hydroxide and hydrogen peroxide, temperature and time of the alkali oxygen bath treatment. The final range was determined by single factor experiments, and the orthogonal experiment was conducted to determine the optimal degumming process parameters, as shown in Table 2.

\section{Degumming rate of bamboo shoot shell fibers}

The degumming rate of bamboo shoot shell fibers was calculated by Equation 1:

Degumming rate $=\frac{W_{1}-W_{2}}{W_{1}} \times 100 \%$

where $\mathrm{W}_{1}$ is weight of bamboo shoot shell fibers before degumming, $\mathrm{W}_{2}$ is weight of bamboo shoot shell fibers after degumming.

\section{Scanning electron microscopy}

The microstructure of the bamboo shoot shell fibers before and after the treatment was analyzed by a Tescan Vega 3 Scanning Electron Microscope (Tesco, Czechoslovakia).

\section{Fourier transform infrared spectroscopy}

Fourier transform infrared spectroscopy (FTIR) was performed on the obtained fibers using a Vertex 70 type spectrometer, by the potassium bromide compression method. The spectra were recorded in the wavenumber range of $400-4000 \mathrm{~cm}^{-1}$.

\section{X-ray diffraction (XRD)}

An X-ray diffractometer (D/Max-2550pc, RIGAKU, Japan) was used to determine the crystallinity of the bamboo shoot shell before and after the treatment. The experimental conditions were as follows: $\mathrm{CuKa}$ radiation (X-ray wavelength: 0.154 $\mathrm{nm}$ ), tube voltage of $40 \mathrm{kV}$, tube current of $30 \mathrm{Ma}$, scanning angle $2 \theta 5-40^{\circ}$ and scanning speed of 5 $\%$ min.

\section{Thermogravimetric analysis}

About $5.0 \mathrm{mg}$ of powdered sample was weighed and put into the sample pool of an SDT 2960 Differential Thermal Gravimetric Analyzer (DSCTGA) (TA Instruments) for thermal performance measurement. The nitrogen flow rate was $50 \mathrm{~mL} / \mathrm{min}$, the heating rate $-10{ }^{\circ} \mathrm{C} \mathrm{min}$, and the temperature range $-20-600{ }^{\circ} \mathrm{C}$. 


\section{RESULTS AND DISCUSSION}

\section{Degumming rate of bamboo shoot shell}

Through the literature review and a large number of experimental studies, it has been found that the main factors affecting the degumming rate are the dosage of sodium hydroxide and hydrogen peroxide, the temperature and time of

Levels of orthogonal factors in degumming experiment of bamboo shoot shell fibers

\begin{tabular}{ccccc}
\hline & \multicolumn{4}{c}{ Factors } \\
\cline { 2 - 5 } Levels & $\begin{array}{c}\mathrm{A} \\
\mathrm{NaOH} \text { concentration } \\
(\mathrm{g} / \mathrm{L})\end{array}$ & $\begin{array}{c}\mathrm{B} \\
\mathrm{H}_{2} \mathrm{O}_{2} \text { concentration } \\
(\mathrm{mL} / \mathrm{L})\end{array}$ & $\begin{array}{c}\mathrm{C} \\
\text { Temperature } \\
\left({ }^{\circ} \mathrm{C}\right)\end{array}$ & $\begin{array}{c}\text { Time } \\
(\mathrm{h})\end{array}$ \\
\hline 1 & 18 & 24 & 85 & 2 \\
2 & 20 & 28 & 90 & 2.5 \\
3 & 22 & 32 & 95 & 3 \\
\hline
\end{tabular}

Table 2

Orthogonal design factors and test data of degumming bamboo shoot shell fibers

\begin{tabular}{cccccc}
\hline No. & $\mathrm{A}$ & $\mathrm{B}$ & $\mathrm{C}$ & $\mathrm{D}$ & Test indicator \\
\hline 1 & 1 & 1 & 1 & 1 & Degumming rate (\%) \\
2 & 1 & 2 & 2 & 2 & $61.5 \%$ \\
3 & 1 & 3 & 3 & 3 & $67.0 \%$ \\
4 & 2 & 1 & 2 & 3 & $68.5 \%$ \\
5 & 2 & 2 & 3 & 1 & $59.5 \%$ \\
6 & 2 & 3 & 1 & 2 & $68.5 \%$ \\
7 & 3 & 1 & 3 & 2 & $64.5 \%$ \\
8 & 3 & 2 & 1 & 3 & $56.5 \%$ \\
9 & 3 & 3 & 2 & 1 & $53.0 \%$ \\
$\mathrm{k}_{1}$ & 64.11 & 61.47 & 61.16 & 57.26 & \\
$\mathrm{k}_{2}$ & 62.37 & 60.24 & 59.66 & 65.59 & \\
$\mathrm{k}_{3}$ & 57.80 & 62.56 & 63.45 & 61.43 & \\
$\mathrm{R}$ & 6.31 & 2.32 & 3.79 & 8.33 & \\
Main $\rightarrow$ Secondary & $\mathrm{DACB}$ & $\mathrm{A}_{1} \mathrm{~B}_{3} \mathrm{C}_{3} \mathrm{D}_{2}$ \\
Optimal scheme & \multicolumn{7}{c}{} \\
\hline
\end{tabular}

Firstly, the bamboo shoot shell fiber was pretreated and degummed by ultrasonic waves, and a certain amount of sodium hydroxide was added to bath, which made the structure of the material loose and thus improved the subsequent degumming effect. The bamboo shoot shell fibers were degummed by alkali and hydrogen peroxide in the same dissolving bath. Alkali could dissolve hemicelluloses and gum in the bamboo shoot shell, while also removing other impurities. At the same time, it can provide an alkaline reaction environment for hydrogen peroxide. Properly stirring during the addition of the hydrogen peroxide solution prevents the bubbles generated by the hydrogen peroxide from producing an upward force, pushing the fibers to move from bottom to top. Stirring by an external force is the process. The optimum degumming process was determined by the orthogonal test, using 4 factors and 3 levels. Table 1 shows the orthogonal factor level of the degumming experiment of bamboo shoot shell fibers, and Table 2 presents the orthogonal test results.

Table 1 
It can be seen from Table 2 that the order of the factors affecting the degumming rate is $\mathrm{D}>\mathrm{A}$ $>\mathrm{C}>\mathrm{B}$. The optimal values obtained by the orthogonal test are the following: alkali concentration of $20 \mathrm{~g} / \mathrm{L}$, hydrogen peroxide concentration of $32 \mathrm{~g} / \mathrm{L}$, temperature of $95{ }^{\circ} \mathrm{C}$, treatment time of $2.5 \mathrm{~h}$. The corresponding degumming rate of the bamboo shoot shell fibers was of $70.07 \%$.

\section{Morphological structure}

Figure 1 shows the surface morphology of the bamboo shoot shell fiber. It can be seen from Figure 1 that the surface of the untreated bamboo shoot shell fibers is rough, with many nodal lines, and there are many colloidal particles on the surface. After the treatment, the nodal pattern on the surface of the bamboo shoot shell fibers is obviously reduced, the gum is basically removed, and the surface becomes smooth. It can be seen that the bamboo shoot shell fibers are actually a fiber bundle formed by the association of multiple single fibers, whose appearance is similar to that of ramie fibers. There are grooves and cracks on the surface of the bamboo shoot shell fibers. The surface structure of the bamboo shoot shell fibers is conducive to water transmission, which means that the fabric made from bamboo shoot shell fibers will have excellent moisture permeability.

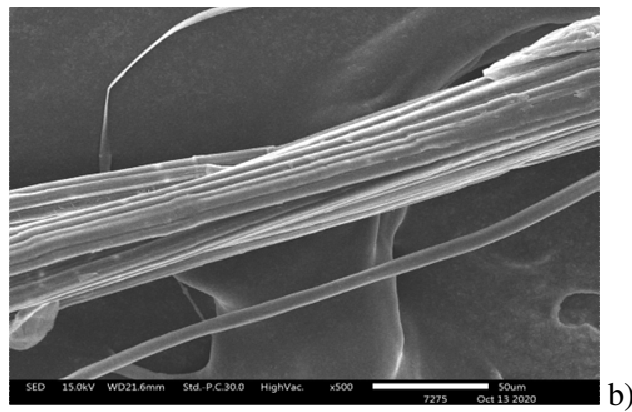

Figure 1: Surface morphology of raw (a) and degummed (b) bamboo shoot shell fibers

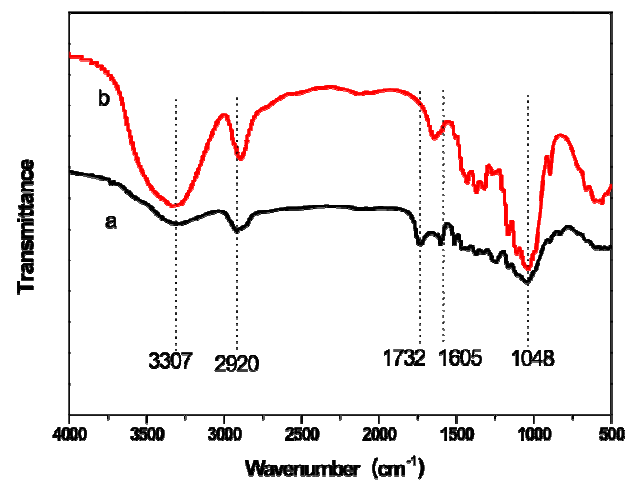

Figure 2: FTIR spectra of raw (a) and degummed (b) bamboo shoot shell fibers

\section{FTIR analysis}

Figure 2 illustrates the infrared spectra of the bamboo shoot shell fibers before and after the treatment. The strong absorption peak at $3307 \mathrm{~cm}^{-1}$ is caused by the stretching vibration of the $-\mathrm{OH}$ group, the absorption peak at $2920 \mathrm{~cm}^{-1}$ belongs to the stretching vibration of the $\mathrm{C}-\mathrm{H}$ group, that at $1732 \mathrm{~cm}^{-1}$ corresponds to the stretching vibration peak of $\mathrm{C}=\mathrm{O}$ of the acetyl group, and the absorption peak at $1605 \mathrm{~cm}^{-1}$ is assigned to the $\mathrm{C}-\mathrm{C}$ of the aromatic ring. The symmetric stretching vibration peak at $1732 \mathrm{~cm}^{-1}$ is the characteristic peak of lignin. $^{23}$

The absorption peak at $1048 \mathrm{~cm}^{-1}$ is caused by the $\mathrm{C}-\mathrm{O}$ stretching vibration of the $\mathrm{C}-\mathrm{O}-\mathrm{C}$ ring. Compared with the untreated bamboo shoot shell fiber, the peak value of the degummed bamboo shoot shell fiber at $2905 \mathrm{~cm}^{-1}$ is lower, indicating 
that the hemicellulose content is lower, and the peak intensity at $1732 \mathrm{~cm}^{-1}$ and $1605 \mathrm{~cm}^{-1}$ is weaker, indicating that the lignin content is lower. The strength of the peak at $3308 \mathrm{~cm}^{-1}$, attributed to cellulose, increased. The analysis of the infrared spectra shows that the bamboo shoot shell fibers mainly contained cellulose, lignin and hemicelluloses.

\section{$\mathrm{X}$-ray diffraction analysis}

Figure 3 shows the X-ray diffraction patterns of the bamboo shoot shell fibers before and after the treatment. As may be remarked, the XRD patterns of the fibers before and after degumming are basically the same. For the degummed fiber, the diffraction peaks shifted a little, but the crystal form belonging to cellulose I did not change. ${ }^{18}$ After degumming, the diffraction peaks of the bamboo shoot shell fiber reached $2 \theta$ values of $16.2,22.2$ and $34.8^{\circ}$, corresponding to the 101 , 002 and 040 planes, respectively.

By using the X-ray diffraction analysis

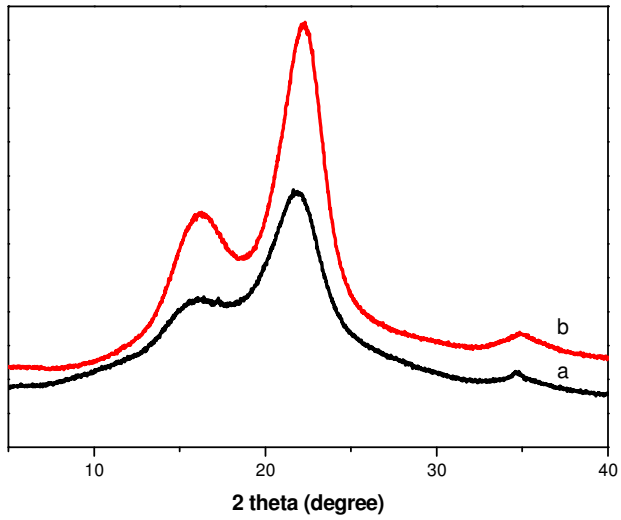

Figure 3: X-ray diffraction patterns of raw (a) and degummed (b) bamboo shoot shell fibers
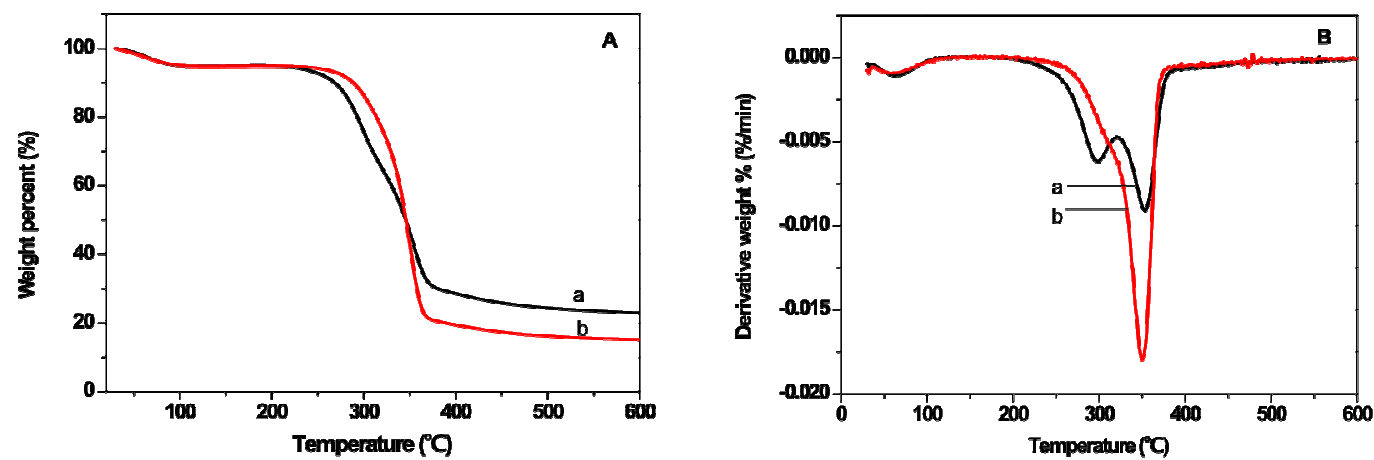

Figure 4: TG (A) and DTG (B) diagrams of raw (a) and degummed (b) bamboo shoot shell fibers

From $230{ }^{\circ} \mathrm{C}$ to $270{ }^{\circ} \mathrm{C}$, a weight loss of about $5 \%$ was recorded, which was mainly due to the degradation of hemicelluloses. In the range of 270-380 ${ }^{\circ} \mathrm{C}$, the weight loss increased sharply, software MDI Jade 6.0, the crystallinity of the bamboo shoot shell fibers before the treatment was determined to be of about $43.5 \%$, while after the treatment it reached $58.7 \%$. This is mainly due to the removal of lignin, hemicelluloses, water soluble matter and pectin from the fibers, thus the proportion of the crystalline region increased, so the crystallinity of the fibers enhanced.

\section{Thermal performance}

Figure 4 presents the TG and DTG curves of the bamboo shoot shell fibers before and after degumming. It can be seen from Figure 4 (A and B) that, both before and after the degumming treatment, the bamboo shoot shell fibers underwent the first stage of weight loss, of about $4 \%$, from 30 to $210{ }^{\circ} \mathrm{C}$. This weight loss is explained by the evaporation of adsorbed water from the fiber (intra- and intermolecular dehydration reactions), as well as the degradation of volatile matter in bamboo shoot shell fiber. 
higher. This can be explained by the fact that the crystallinity of the degummed bamboo shell fiber is higher than that of the raw material, which indicates that the thermal stability of the bamboo shell fiber is improved after the degumming treatment.

\section{CONCLUSION}

In the present study, bamboo shoot shell fibers were extracted by the ultrasound-assisted alkalioxygen bath method. The extracted bamboo shoot shell fibers presented smooth surface, good quality and high cellulose content. In terms of chemical composition, the bamboo shoot shell fibers contained cellulose, hemicelluloses, lignin, pectin, waxy fats and other substances. The degumming of bamboo shoot shell fibers was performed to remove hemicelluloses and lignin. After the experimental study, it could be concluded that the degumming effect of the ultrasonic pretreatment on bamboo shoot shell fiber is remarkable. The addition of a certain amount of sodium hydroxide to the ultrasonication process and the "hollow effect" generated by the ultrasonic waves improve the effects of subsequent degumming, while using hydrogen peroxide and sodium hydroxide in the same bath can remove more gum. Bamboo shoot shell is rich in cellulose and thus is a potential natural fiber resource, while the approach proposed in this study offers a possibility to valorize it. This method can also be applied to other raw biomass materials and this will be investigated in future research.

ACKNOWLEDGEMENTS: This work was supported by National Natural Science Foundation of China Youth Fund (51503162); general project of Hubei Provincial Natural Science Foundation (2016cfb459); National Innovation Training Program for College Students (201910495014); Technical Innovation Program of Hubei Province (2019aaa005); Innovation Training Program for University Students of Hubei Province (s201910495063).

\section{REFERENCES}

1 I. Siro and D. Plackett, Cellulose, 17, 459 (2010), https://doi.org/10.1007/s10570-010-9405-y

2 C. Miao and W. Y. Hamad, Cellulose, 20, 2221 (2013), https://doi.org/10.1007/s10570-013-0007-3

S. Karimi, P. M. Tahir, A. Karimi, A. Dufresne and A. Abdulkhani, Carbohyd. Polym., 101, 878 (2014), https://doi.org/10.1016/j.carbpol.2013.09.106
4 Y. Li, H. Ren and A. J. Ragauskas, Nano-Micro Lett., $\quad 2, \quad 89 \quad$ (2010), https://doi.org/10.1007/BF03353624

5 O. Nechyporchuk, M. N. Belgacem and F. Pignon, Biomacromolecules, 17, $2311 \quad$ (2016), https://doi.org10.1021/acs.biomac.6b00668

6 W. Liese, J. Bamboo Rattan, 2, 189 (2003), https://doi.org/10.1163/156915903322320793

M. J. Chung and S. Y. Wang, Wood Sci., 63, 473 (2017), https://doi.org/10.1007/s10086-017-1647-y

S. Benyoucef, D. Harrache, S. Djaroud, G. M. Daniel and G. Miguel, Cellulose, 27, 8169 (2020), https://doi.org/10.1007/s10570-020-03349-6

9 W. Chen, H. Yu, Y. Liu, P. Chen, M. Zhang et al., Carbohyd. Polym., 83, $1804 \quad$ (2011), https://doi.org/10.1016/j.carbpol.2010.10.040

10 R. Li, W. Xu, L. Fang, P. X. Cao and X. Guo, Wood Res., $\quad$ 62, $825 \quad$ (2017), http://www.woodresearch.sk/wr/201705/15.pdf

11 R. D. Silva and N. Byrne, Carbohyd. Polym., 174, 89

(2017),

https://doi.org/10.1016/j.carbpol.2017.06.042

12 H. Liu, P. He, L. He, Q. Li, J. Cheng et al., Carbohyd. Polym., 201, $189 \quad$ (2018), https://doi.org/10.1016/j.carbpol.2018.08.024

13 L. Ye, J. Zhang, J. Zhao and S. Tu, Bioresour. Technol., $\quad 153, \quad 147 \quad$ (2014), https://doi.org/10.1016/j.biortech.2013.11.070

14 W. Gong, Z. Ran, F. Ye and G. Zhao, Food Chem., 228, 455 (2017),

https://doi.org/10.1016/j.foodchem.2017.02.017

15 L. J. Zheng and C. W. Yu, Journal of Donghua University (Natural Science Edition), 28, 94 (2002), https://doi.org/10.2753/CSH0009-4633350347

16 B. A. Amel, M. T. Paridah, R. Sudin, U. Anwar and A. S. Hussein, Ind. Crop. Prod., 46, 117 (2013), https://doi.org/10.1016/j.indcrop.2012.12.015

17 W. Gong, Z. Ran, F. Ye and G. Zhao, Food Chem., 228, 455 (2017), https://doi.org/10.1016/j.foodchem.2017.02.017

18 R. Y. Ding, X. Q. Zhang and C. W. Yu, J. Nat. Fiber, 11, $13 \quad$ (2014), https://doi.org/10.1080/15440478.2013.824851

19 S. Ajouguim, K. Abdelouahdi and M. Waqif, Cellulose, 26, $1503 \quad$ (2019), https://doi.org/10.1007/s10570-018-2181-9

20 X. Zhang, G. Han, Y. Zhang, Q. Wang, W. Jiang et al., Chin. J. Biotechnol., 30, 734 (2014), https://doi.org/10.13345/j.cjb.140062

21 F. M. Pelissari, P. J. D. A. Sobral and F. C. Menegalli, Cellulose, 21, 417 (2014), https://doi.org/10.1007/s10570-013-0138-6

22 J. H. Wang and G. N. Ramaswamy, Text. Res. J., 73, 339

(2003), https://doi.org/10.1177/004051750307300411

23 M. M. Ibrahim, W. K. Zawawy, Y. Juttke, A. Koschell and T. Heinze, Cellulose, 20, 2403 (2013), https://doi.org/10.1007/s10570-013-9992-5 